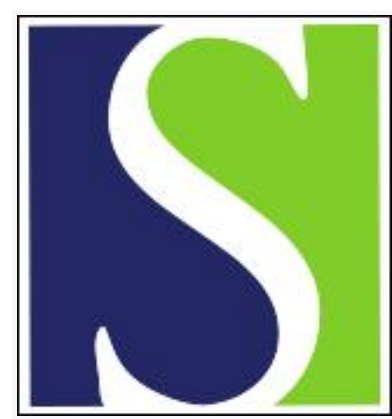

Scand J Work Environ Health 2011;37(4):288-297

https://doi.org/10.5271/sjweh.3149

Published online: 15 Feb 2011, Issue date: Jul 2011

Effect of job maintenance training program for employees with chronic disease - a randomized controlled trial on self-efficacy, job satisfaction, and fatigue

by Varekamp I, Verbeek JH, de Boer A, van Dijk FJH

Affiliation: Coronel Institute of Occupational Health, Academic Medical Center, University of Amsterdam, Amsterdam, the Netherlands. i.varekamp@amc.nl

Refers to the following text of the Journal: 2003;29(2):134-142

Key terms: chronic disease; empowerment; fatigue; job maintenance; job satisfaction; occupational health; psychological distress; randomized controlled trial; RCT; self-efficacy; training; work-related problem

This article in PubMed: www.ncbi.nlm.nih.gov/pubmed/21321787 


\title{
Effect of job maintenance training program for employees with chronic disease - a randomized controlled trial on self-efficacy, job satisfaction, and fatigue
}

\author{
by Inge Varekamp, PhD, ${ }^{1}$ Jos H Verbeek, PhD, ${ }^{1,2}$ Angela de Boer, PhD, ${ }^{1}$ Frank JH van Dijk, PhD ${ }^{1}$
}

\begin{abstract}
Varekamp I, Verbeek JH, de Boer A, Van Dijk FJH. Effect of job maintenance training program for employees with chronic disease - a randomized controlled trial on self-efficacy, job satisfaction, and fatigue. Scand J Work Environ Health 2011;37(4):288-297. doi:10.5271/sjweh.3149
\end{abstract}

\begin{abstract}
Objective Employees with a chronic physical condition may be hampered in job performance due to physical or cognitive limitations, pain, fatigue, psychosocial barriers, or because medical treatment interferes with work. This study investigates the effect of a group-training program aimed at job maintenance. Essential elements of the program are exploration of work-related problems, communication at the workplace, and the development and implementation of solutions.
\end{abstract}

Methods Participants with chronic physical diseases were randomly assigned to the intervention $(\mathrm{N}=64)$ or control group ( $\mathrm{N}=58)$. Participants were eligible for the study if they had a chronic physical disease, paid employment, experienced work-related problems, and were not on long-term $100 \%$ sick leave. Primary outcome measures were self-efficacy in solving work- and disease-related problems (14-70), job dissatisfaction (0-100), fatigue (20-140) and job maintenance measured at 4-, 8-, 12- and 24-month follow-up. We used GLM repeated measures for the analysis.

Results After 24 months, loss to follow-up was 5.7\% (7/122). Self-efficacy increased and fatigue decreased significantly more in the experimental than the control group $[10$ versus 4 points $(\mathrm{P}=0.000)$ and 19 versus 8 points $(\mathrm{P}=0.032)$, respectively]. Job satisfaction increased more in the experimental group but not significantly [6 versus 0 points $(\mathrm{P}=0.698)$ ]. Job maintenance was $87 \%$ in the experimental and $91 \%$ in the control group, which was not a significant difference. Many participants in the control group also undertook actions to solve work-related problems.

Conclusions Empowerment training increases self-efficacy and helps to reduce fatigue complaints, which in the long term could lead to more job maintenance. Better understanding of ways to deal with work-related problems is needed to develop more efficient support for employees with a chronic disease.

Key terms empowerment; occupational health; psychological distress; RCT; training; work-related problem.

Many employees with a chronic disease manage their work well, but others are hampered in job performance due to health complaints, physical or cognitive limitations, pain, fatigue, or medical requirements. Lerner et al (1) found that, depending on the medical condition, $22-49 \%$ of employees with various chronic conditions experienced difficulties in meeting physical work demands, and $27-58 \%$ experienced difficulties in meeting psychosocial work demands. Employees themselves point out the importance of many psychosocial barriers, such as lack of support and understanding of colleagues and line managers (2-4), social stress and lack of job autonomy (5), reluctance to disclose and fear that others may see one as being more favored than colleagues (6), inability to cope with illness (2) or to set limits, a negative self-image, and feelings of hopelessness relating to employability (7). Fatigue is a very common complaint among patients with chronic disease (8), and fatigue scores are substantially higher among employees with a chronic disease than among non-chronically ill employees (9). The same holds for psychological distress (9). Fatigue is assumed to be directly caused by disease and psychological distress (10).

1 Coronel Institute of Occupational Health, Academic Medical Center, University of Amsterdam, Amsterdam, the Netherlands.

2 Finnish Institute of Occupational Health, Knowledge Transfer Team, Kuopio, Finland.

Correspondence to: Inge Varekamp, Coronel Institute of Occupational Health, Academic Medical Center, University of Amsterdam, Amsterdam, the Netherlands. [E-mail: i.varekamp@amc.uva.nl] 
Employment rates for individuals with rheumatoid arthritis, inflammatory bowel disease, cancer, and chronic obstructive pulmonary disease are substantially lower than for healthy persons (11-17); for dialysis patients, people with Parkinson's disease, or multiple sclerosis, the employment situation is even worse $(5,18-20)$.

Over the past several decades, social policy in industrialized countries concentrated primarily on stimulating persons with chronic conditions or handicaps to enter or re-enter the labor market. More recently, attention has been paid to efforts that help employees to stay at work $(21,22)$. A review of empowerment-based interventions aimed at job maintenance shows that there is limited evidence that these are effective at enhancing self-efficacy, implementation of work accommodations, and job maintenance (23). For that reason, we developed a group-based training program for employees with a chronic physical disease who experience work-related problems.

The objective of this study is to evaluate the effect of the training program, which aims to solve work-related problems and consequently lessen psychological distress and fatigue. Fatigue and job dissatisfaction have been shown to be predictors for work disability and, as a consequence, job loss $(21,24,25)$. We hypothesize that perceived self-efficacy will improve and that fatigue and job dissatisfaction will decrease to a greater extent in the experimental than the control group. We assume that this contributes to job maintenance in the experimental group (figure 1), but we expect to be unable to find an effect in this respect, since this asks for a very large study sample.

\section{Methods}

\section{Intervention}

The training program focused on solving work-related problems. A step-wise approach was used: first, workrelated problems were explored and clarified; second, communication at work was addressed; and third, solutions were developed and realized. The group-training program had one trainer and eight participants and consisted of six three-hour sessions every two weeks, with a seventh session two months after the sixth. This was combined with three individual counseling sessions. Every

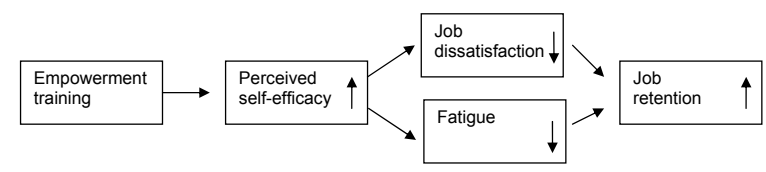

Figure 1. Theoretical model of the impact of empowerment training on perceived self-efficacy, job satisfaction and fatigue, resulting in less job loss. group session focused on a single theme: (i) exploration and clarification of practical and psychosocial workrelated problems, (ii) insight into feelings and thoughts about having a chronic disease, (iii) communication in daily work situations and role play, (iv) legislation and facilities for disabled employees, (v) communication, assertiveness, and role play, (vi) a SMART (Specific, Measurable, Attainable, Relevant, Time-bound) plan to solve problems, (vii) and a follow-up meeting.

The program has an empowerment perspective: its aim is to enhance the knowledge, self-awareness and skills (especially communication skills) of the individuals, in order to help them solve problems at work (26). The program is based on the social learning theory of Bandura (27) that assumes that behavior change and maintenance are a function of both expectations about the outcomes of behavior and expectations about one's ability to engage in this behavior. These self-efficacy beliefs are specific to particular situations such as work situations. They may be enhanced in a training situation by performance accomplishments, vicarious experience, and verbal persuasion. A comprehensive description of the development, set-up, and contents of the training is published elsewhere (28).

\section{Study design and power analysis}

The study was designed as a randomized controlled trial (RCT). Participants were asked to complete a baseline questionnaire before randomization and four follow-up questionnaires at 4, 8, 12, and 24 months. Persons in the control group were not restricted to any protocol, and we assumed that they would not always receive appropriate care for work-related problems and would not organize this for themselves.

The sample size is based on detecting a difference in fatigue, as measured by the fatigue severity subscale of the checklist individual strength [CIS (29)]. Power calculations were made to detect a mean difference of 15 points with an alpha of 0.05 and a power of $80 \%$, based on Stulemeijer et al (30). Based on this study, 25 participants were required in both the experimental and control groups. We expected a somewhat lower effect size and decided to take a larger sample: 8 training groups with 64 participants and a control group comprised of 64 participants.

The Medical Ethics Committee of the Academic Medical Center in Amsterdam approved the study, but deemed an ethical review unnecessary because they did not perceive the study to be "medical" research.

\section{Recruitment of participants and eligibility criteria}

Participants were recruited via outpatient clinics, occupational health services, patient organizations, and 
employers. Presentations were given at meetings of patient organizations, at a national conference on chronic diseases, and for medical professionals of outpatient clinics and occupational health services. A leaflet, also available digitally, described the set-up and focus of the training program: (i) consequences of a chronic disease for work functioning, (ii) communication about this with colleagues and the supervisor, (iii) prevention of overburdening, and (iv) the possibilities of work adaptations. Patient organizations and employers were asked to publish calls for participation in their magazines, electronic newsletters, websites, or in-house media. Candidates had to apply independently by telephone, even when referred by medical professionals.

Participants were eligible for the study if they had a self-reported chronic physical disease, a paid job, and experienced problems at work. Workers with predominantly psychiatric conditions were excluded; however, people with a chronic physical disease in combination with depressive feelings were not excluded. Workers on long-term 100\% sick leave were only included if they expected to return to work soon. The eligibility criteria were checked at the moment of application by telephone, with the exception of the criterion "experience problems at work". For practical reasons, we checked this after randomization during the first individual consultation with the trainer, which also functioned as the admission interview.

\section{Randomization}

Candidates received the baseline questionnaire and an informed consent form six weeks before the start of the training program. A first reminder was sent by mail and a second reminder was carried out via telephone or email. The individuals who had sent back the baseline questionnaire were randomized. Block randomization for each of the eight training programs was performed with the help of a computer program that generates random numbers. Participants randomized in the training group received an invitation for the admission interview with the trainer. If participants decided not to have an admission interview or if they did not meet the inclusion criterion "experience problems at work", they were excluded. In that case, because we wanted a full training group, we randomly picked a person from the control group to participate in the intervention group.

Neither the participants nor the primary researcher were blinded to the treatment assignment. Participants could not be blinded due to this form of intervention. Blinding the researcher was impractical for the data analysis. Assessment bias by the researcher was probably low because these were self-reported data. Data entry decisions in the case of ambiguous data were recorded.

\section{Outcome measures}

We used the following primary outcome measures: (i) self-efficacy in solving work- and disease-related problems, (ii) fatigue, and (iii) job dissatisfaction. We developed a situation-specific self-efficacy questionnaire according to the principles formulated by Bandura (31). This questionnaire measures the perceived self-efficacy in solving work- and disease-related problems with 14 5-point Likert scale items and had a Crohnbach's alpha reliability of 0.80 at baseline and 0.87 after 12 months. Fatigue was measured with the CIS (29). A score of $\geq 76$ is considered a fatigue level that puts the individual at risk for sick leave or work disability (32). Job dissatisfaction was measured by using a subscale of the Dutch questionnaire on perception and judgment of work (33).

Job maintenance interventions are rare and evidence of their working mechanisms is lacking. Thus, we decided to use a number of secondary outcome measures: (i) job maintenance itself, (ii) work-related problems, (iii) quality of life, (iv) acquired work accommodations, (v) burnout, and (vi) worries about work. Job maintenance was defined as having a paid job. Full-time sick leave of $>6$ months, combined with the expectation that a return to work is improbable or impossible, was defined as job loss. Work-related problems due to the health condition were measured with 8 items: (i) having problems with specific work tasks, (ii) finishing work, (iii) arranging the workplace, (iv) commuting, (v) communicating with colleagues, (vi) communicating with supervisors, (vii) accepting the disease, and (viii) balancing work and life at home. The 3-answer categories were counted as: 0 (no), 1 (yes, slightly), or 2 (yes, severely) and were added up to a summary measure. Quality of life was measured with the validated Standard Form 12 (SF-12) (34). Work accommodations were measured with Kremer et al's work accommodations list (17). Burnout was measured by the Utrecht burnout scale (35). The measure "worries about work" was calculated with a subscale of the Dutch questionnaire on perception and judgment of work (33).

Participants in the control group were asked after four and eight months whether they themselves or others had taken measures to solve work-related problems.

\section{Statistical analysis}

Statistical analyses were performed with SPSS version 16.0 (SPSS Inc, Chicago, IL, USA) according to the intention-to-treat principle. Continuous outcome measures were analyzed at baseline and follow-up with the two-way mixed between-within subjects analysis of variance. General linear models were chosen for this repeated measurement analysis. In case of a significant $(\mathrm{P}<0.05)$ Mauchly's W test for sphericity, the corrected 
Greenhause Geissers F was presented. We first evaluated the effect of time only and subsequently the effect of the intervention by studying the interaction effect of time and group. In the case of missing questionnaires at 8- or 12-month follow-up, the last observations were carried forward and used for the repeated measurements. Cases were not analyzed if questionnaires were missing at 4 or 24 months. Participants who were not at work because of long-term sick leave or temporary job loss at a measurement moment were not included in the analysis of work-related outcomes.

\section{Results}

\section{Study population}

We recruited participants for the training program and the study from June 2006 until January 2008. The training programs were executed between November 2006 and September 2008. A total of 142 employees applied for the study, of which 132 sent back the baseline questionnaire and were randomly placed in each study group (figure 2). Ten people dropped out of the intervention group before the intervention started. The final study group consisted of 122 participants, 64 of whom were allocated to the training group and 58 to the control group.

Three participants in the intervention group dropped out of the training program due to dissatisfaction with the program $(\mathrm{N}=2)$ and urgent medical treatment $(\mathrm{N}=1)$, but their data were included. After 4, 8, 12, and 24 months, 122, 119, 116 and 115 participants, respectively, were present in the study population.

The baseline disease characteristics are presented in table 1 . Twenty five percent had musculoskeletal disorders, $23 \%$ had neurological disorders, and $21 \%$ had digestive disorders. Disease duration was ten years on average, and $44 \%$ suffered from $\geq 1$ chronic disorder. Seventy three percent had a score $>76$ on the CIS fatigue scale, indicating a fatigue level at risk for sick leave or disability.

The personal, work and additional medical characteristics are presented in table 2 . The mean age was 46 years. Women, higher-educated persons, and individuals working in the service sector were over-represented. There were slight differences between the experimental group and the control group with regard to gender, education, branch of industry, co-morbidity, sick leave, hindrance at work due to health problems, and work capacity.

Four months after the start of the study, $71 \%$ of the control group stated that they or others had undertaken measures to solve work-related problems; after eight

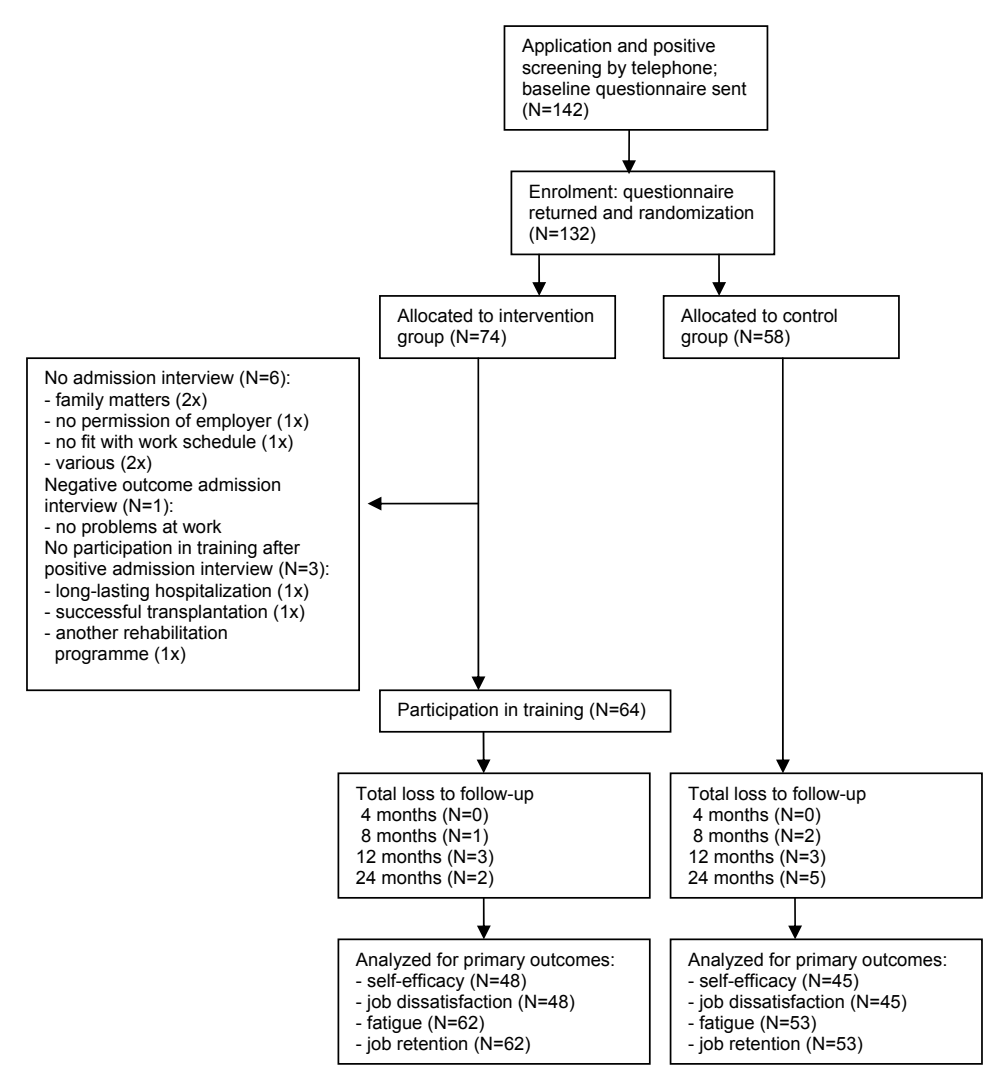

Figure 2. Recruitment, allocation, and study withdrawal of participants 
Table 1. Chronic disease (following the International Classification of Diseases, ICD 10) and other health characteristics of the study population $(\mathrm{N}=122)$. [SD=standard deviation.]

\begin{tabular}{|c|c|c|c|c|}
\hline Chronic disease & $\mathrm{N}$ & $\%$ & Mean & SD \\
\hline $\begin{array}{l}\text { Diseases of the musculoskeletal system } \\
\text { and connective tissue a }\end{array}$ & 30 & 25 & & \\
\hline Diseases of the nervous system ${ }^{b}$ & 28 & 23 & & \\
\hline Diseases of the digestive system ${ }^{c}$ & 25 & 21 & & \\
\hline $\begin{array}{l}\text { Endocrine, nutritional and metabolic } \\
\text { diseases }^{d}\end{array}$ & 10 & 8 & & \\
\hline Neoplasms & 6 & 5 & & \\
\hline Diseases of the respiratory system & 5 & 4 & & \\
\hline Diseases of the circulatory system ${ }^{e}$ & 4 & 3 & & \\
\hline Other diseases ${ }^{f}$ & 14 & 12 & & \\
\hline$\geq 1$ additional chronic diseases & 54 & 44 & & \\
\hline Disease duration in years & & & 10.2 & 9.5 \\
\hline
\end{tabular}

a Including rheumatoid arthritis ( $\mathrm{N}=12$ ), fibromyalgia or other chronic pain $(\mathrm{N}=5)$, systemic lupus erythematosus $(\mathrm{N}=4)$, arthritis $(\mathrm{N}=3)$, and Sjögrens disease $(\mathrm{N}=2)$.

b Including multiple sclerosis ( $N=13)$ and Parkinson's disease $(\mathrm{N}=9)$.

c Including Crohn's disease or colitis ulcerosa (N=24).

d Including diabetes ( $\mathrm{N}=5)$, Graves' disease and other thyroid gland disorders $(\mathrm{N}=4)$.

${ }^{e}$ All heart conditions $(\mathrm{N}=4)$.

${ }^{\mathrm{f}}$ Including HIV/AIDS ( $\left.\mathrm{N}=3\right)$, renal failure $(\mathrm{N}=2)$, visual impairments $(\mathrm{N}=2)$, and other diseases $(\mathrm{N}=7)$.

Table 2. Personal, work and additional medical characteristics of the study population $(\mathrm{N}=122)$. [SD=standard deviation.]

\begin{tabular}{|c|c|c|c|c|c|c|}
\hline & \multicolumn{3}{|c|}{ Experimental $(\mathrm{N}=64)$} & \multicolumn{3}{|c|}{ Control $(\mathrm{N}=58)$} \\
\hline & $\%$ & Mean & SD & $\%$ & Mean & SD \\
\hline Age (years) & & 46.1 & 8.8 & & 45.0 & 8.7 \\
\hline Women & 83 & & & 66 & & \\
\hline $\begin{array}{l}\text { Living alone (not with partner, } \\
\text { children, or parents) }\end{array}$ & 33 & & & 22 & & \\
\hline \multicolumn{7}{|l|}{ Education } \\
\hline Lower & 3 & & & 3 & & \\
\hline Middle & 36 & & & 50 & & \\
\hline Higher & 64 & & & 47 & & \\
\hline \multicolumn{7}{|l|}{ Sector of industry } \\
\hline Agriculture and fishing & 0 & & & 0 & & \\
\hline Industry and construction & 0 & & & 3 & & \\
\hline Commercial services & 27 & & & 55 & & \\
\hline Non-commercial services & 73 & & & 41 & & \\
\hline \multicolumn{7}{|l|}{ Appointment } \\
\hline Hours per week & & 30 & 8.6 & & 32 & 7.5 \\
\hline Days per week & & 4.2 & 0.8 & & 4.3 & 0.7 \\
\hline$\geq 1$ additional chronic diseases & 48 & & & 40 & & \\
\hline $\begin{array}{l}\text { On disability compensation } \\
\text { (partially or 100\%) }\end{array}$ & 25 & & & 25 & & \\
\hline $\begin{array}{l}\text { Sickness absence (number of } \\
\text { days in last } 4 \text { months) }\end{array}$ & & 14 & 20.5 & & 20 & 25.0 \\
\hline \multicolumn{7}{|l|}{$\begin{array}{l}\text { Hindered at work due to health } \\
\text { problems }\end{array}$} \\
\hline No & 3 & & & 5 & & \\
\hline Yes, slightly & 70 & & & 51 & & \\
\hline Yes, severely & 27 & & & 44 & & \\
\hline \multicolumn{7}{|l|}{ Work capacity, physical } \\
\hline (Very) bad & 13 & & & 24 & & \\
\hline Moderate & 55 & & & 47 & & \\
\hline (Very) good & 33 & & & 29 & & \\
\hline \multicolumn{7}{|l|}{ Work capacity, mental } \\
\hline (Very) bad & 14 & & & 19 & & \\
\hline Moderate & 47 & & & 40 & & \\
\hline (Very) good & 39 & & & 41 & & \\
\hline
\end{tabular}

months, $61 \%$ of the control group stated that they or others had undertaken these kinds of measures because of their allocation to the control group. In the control group, 16 participants took actions that resembled the training program (eg, psychosocial support from a psychologist, psychotherapist, social worker, job coach, career coach, or some kind of self-management program).

\section{Primary outcome measures}

Table 3 and figure 3 present the primary outcome measures at baseline and follow-up measurements. After two years, the perceived self-efficacy had increased 10 points for the experimental group, for the greater part in the first four months, and 4 points for the control group. The entire study population improved significantly in the course of two years $(\mathrm{F}=28,7, \mathrm{P}=0.000)$. There was also a significant interaction effect, which means that the intervention had a significant effect in the course of two years $(\mathrm{F}=5,6, \mathrm{P}=0.000)$.

Overall, job dissatisfaction decreased slightly for the experimental group and remained stable for the control group. There was neither a statistically significant effect for time nor a significant interaction effect.

Fatigue decreased 19 points for the experimental group and 8 points for the control group. There was a statistically significant effect for time $(\mathrm{F}=10,0 ; \mathrm{P}=0.000)$ and a significant interaction effect $(\mathrm{F}=2,7 ; \mathrm{P}=0.032)$. Fatigue complaints decreased until the end of the second year in the experimental group; they stabilized during the second year in the control group.

\section{Secondary outcome measures}

After two years, 54 of the 62 participants (87\%) in the experimental group had maintained their job, of which two participants were on short- or long-term sick leave but expecting to return to work. In the control group, 48 of the 53 participants $(91 \%)$ maintained their job, of which four persons were on short- or long-term sick leave but expecting to return to work; one person was dismissed and had become self-employed. Job maintenance was not significantly greater for the control group, with an odds ratio (OR) of 1.42 [95\% confidence interval (95\% CI) 0.44-4.64].

Table 4 presents the other secondary outcome measures at baseline and after 24 months. Physical quality of life improved significantly for both groups, but not more for the experimental than the control group. Mental quality of life improved significantly more for the experimental group. Work-related problems decreased for both groups, but not more so for the experimental group. The number of work accommodations was stable in both groups. The burnout exhaustion, detachment, and competence scales presented a significant improvement 
Table 3. Effect of intervention on self-efficacy, job dissatisfaction, and fatigue. Repeated measurement based on intention-to-treat analysis ( $\mathrm{N}=115)$. [SD=standard deviation; $\mathrm{CIS}=$ checklist individual strength.]

\begin{tabular}{|c|c|c|c|c|c|c|c|c|c|c|}
\hline & \multicolumn{3}{|c|}{ Experimental } & \multicolumn{3}{|c|}{ Control } & \multirow{2}{*}{$\begin{array}{l}\text { Time } \\
\text { effect } \\
\text { (F) }\end{array}$} & \multirow[t]{2}{*}{ P-value } & \multirow{2}{*}{$\begin{array}{c}\text { Time } \times \\
\text { interaction } \\
\text { effect (F) }\end{array}$} & \multirow[t]{2}{*}{ P-value } \\
\hline & $N$ & Mean & SD & $\mathrm{N}$ & Mean & SD & & & & \\
\hline Self-efficacy (14-70) a & 48 & & & 45 & & & & & & \\
\hline Baseline & & 45.4 & 8.4 & & 50.0 & 9.0 & & & & \\
\hline 4-month follow-up & & 53.1 & 8.3 & & 52.3 & 10.2 & & & & \\
\hline 8-month follow-up & & 54.9 & 8.4 & & 53.7 & 9.0 & & & & \\
\hline 12-month follow-up & & 55.3 & 10.2 & & 53.7 & 9.6 & & & & \\
\hline 24-month follow-up & & 55.8 & 8.5 & & 54.4 & 9.5 & 28.7 & 0.000 & 5.6 & 0.000 \\
\hline Job dissatisfaction $(0-100)^{\text {a }}$ & 48 & & & 45 & & & & & & \\
\hline Baseline & & 21.4 & 25.8 & & 23.0 & 31.9 & & & & \\
\hline 4-month follow-up & & 18.4 & 26.5 & & 22.8 & 32.5 & & & & \\
\hline 8-month follow-up & & 19.5 & 28.7 & & 26.8 & 29.9 & & & & \\
\hline 12-month follow-up & & 19.4 & 28.9 & & 24.9 & 32.7 & & & & \\
\hline 24-month follow-up & & 15.0 & 22.3 & & 23.1 & 28.3 & 0.9 & 0.480 & 0.6 & 0.698 \\
\hline Fatigue CIS $(20-140)^{\text {a }}$ & 62 & & & 53 & & & & & & \\
\hline Baseline & & 88.2 & 22.3 & & 90.1 & 20.7 & & & & \\
\hline 4-month follow-up & & 84.9 & 25.7 & & 82.9 & 24.4 & & & & \\
\hline 8-month follow-up & & 77.0 & 24.2 & & 84.0 & 24.5 & & & & \\
\hline 12-month follow-up & & 74.9 & 25.9 & & 80.8 & 27.5 & & & & \\
\hline 24-month follow-up & & 69.6 & 28.2 & & 81.9 & 24.9 & 10.0 & 0.000 & 2.7 & 0.032 \\
\hline
\end{tabular}

a High value=more of the measured concept. Figures between parentheses are minimum and maximum values.

Table 4. Secondary outcome measures, at baseline and after two years. Repeated measurement based on intention-to-treat analysis $(\mathrm{N}=115)$. [SD=standard deviation; $\mathrm{SF}=$ standard form.]

\begin{tabular}{|c|c|c|c|c|c|c|c|c|c|c|}
\hline & \multicolumn{3}{|c|}{ Experimental } & \multicolumn{3}{|c|}{ Control } & \multirow{2}{*}{$\begin{array}{l}\text { Time } \\
\text { effect } \\
(\mathrm{F})\end{array}$} & \multirow[t]{2}{*}{ P-value } & \multirow{2}{*}{$\begin{array}{c}\text { Time } \times \\
\text { interaction } \\
\text { effect }(F)\end{array}$} & \multirow[t]{2}{*}{ P-value } \\
\hline & $\mathrm{N}$ & Mean & SD & $\mathrm{N}$ & Mean & SD & & & & \\
\hline Quality of life SF-12 physical (0-100) a & 61 & & & 51 & & & & & & \\
\hline Baseline & & 44.9 & 24.2 & & 41.7 & 19.7 & & & & \\
\hline 24-month follow-up & & 57.0 & 26.9 & & 49.7 & 27.8 & 6.7 & 0.000 & 1.0 & 0.428 \\
\hline Quality of life SF-12 mental (0-100) a & 62 & & & 53 & & & & & & \\
\hline Baseline & & 45.3 & 17.5 & & 43.5 & 18.6 & & & & \\
\hline 24-month follow-up & & 58.2 & 16.0 & & 50.0 & 17.9 & 9.0 & 0.000 & 3.0 & 0.019 \\
\hline Work-related problems $(0-16)$ & 48 & & & 45 & & & & & & \\
\hline Baseline & & 6.8 & 2.9 & & 6.8 & 2.8 & & & & \\
\hline 24-month follow-up & & 3.8 & 2.6 & & 4.7 & 2.7 & 24.4 & 0.000 & 1.9 & 0.105 \\
\hline Number of work accommodations $(0-17)$ & 54 & & & 48 & & & & & & \\
\hline Baseline & & 2.9 & 2.1 & & 3.4 & 2.5 & & & & \\
\hline 24-month follow-up & & 2.8 & 2.6 & & 3.4 & 2.6 & 0.7 & 0.549 & 1.5 & 0.208 \\
\hline Burnout, exhaustion $(0-6)^{b}$ & 48 & & & 43 & & & & & & \\
\hline Baseline & & 3.3 & 1.4 & & 3.4 & 1.4 & & & & \\
\hline 24-month follow-up & & 2.5 & 1.5 & & 2.6 & 1.3 & 10.0 & 0.000 & 0.2 & 0.940 \\
\hline Burnout, detachment $(0-6)^{b}$ & 48 & & & 42 & & & & & & \\
\hline Baseline & & 1.9 & 1.3 & & 2.0 & 1.2 & & & & \\
\hline 24-month follow-up & & 1.5 & 1.1 & & 1.9 & 1.2 & 2.6 & 0.044 & 0.7 & 0.602 \\
\hline Burnout, competence $(0-6)^{b}$ & 48 & & & 43 & & & & & & \\
\hline Baseline & & 4.2 & 0.9 & & 4.2 & 0.9 & & & & \\
\hline 24-month follow-up & & 4.5 & 0.9 & & 4.5 & 0.8 & 4.4 & 0.002 & 1.3 & 0.281 \\
\hline Worries about work $(0-100)^{b}$ & 48 & & & 43 & & & & & & \\
\hline Baseline & & 44.8 & 39.6 & & 39.5 & 39.0 & & & & \\
\hline 24-month follow-up & & 29.2 & 39.0 & & 33.1 & 36.1 & 5.4 & 0.001 & 2.0 & 0.105 \\
\hline
\end{tabular}

a Quality of life: high value=high quality. Figures between parentheses are minimum and maximum values.

${ }^{\mathrm{b}}$ Burnout and worries about work: high value=more of the measured concept. Figures between parentheses are minimum and maximum values. 
in time, but the experimental group did not perform better than the control group. Worries about work decreased significantly, but the experimental group did not perform better than the control group.

\section{Additional analyses}

The experimental and control groups differed slightly in the number of chronic diseases, hindrance at work due to health problems, and work capacity. We did an extra repeated measurements analysis for the primary outcome measures with physical work capacity at baseline as a covariate. The results were similar for the outcome measures self-efficacy, and job dissatisfaction. For fatigue, the F-value indicating the interaction effect of time and group dropped from 2.7 to 2.3 and the corresponding significance level dropped from $\mathrm{P}=0.032$ to $\mathrm{P}=0.061$.

\section{Discussion}

At the two-year follow-up, self-efficacy and fatigue improved significantly more in the experimental than the control group. Job dissatisfaction did not significantly differ between the two groups. Even though many of the secondary outcome measures improved for the whole group, only mental quality of life improved significantly more in the experimental group. The number of work accommodations did not increase.

This study has several strong features. We evaluated a theory-driven, carefully developed and pilot-tested intervention. The quality of delivery of the intervention was good with most participants involved in all sessions. We used an RCT design that controlled for influences other than the intervention. In addition, we had a long follow-up and measured the outcome five times, which provides the opportunity to study how the intervention affects outcomes over time. We had a very high response rate that remained stable over time and increases the reliability of the results. The process evaluation showed that the majority of the participants were very satisfied about the training program and thought that it had an effect on how they dealt with various work- or diseaserelated problems. Only two participants dropped out due to dissatisfaction with the intervention (36).

We hypothesized an effect on fatigue based on a study of chronic fatigue syndrome (29). However, in contrast to this syndrome, which often reacts positively to appropriate treatment, most chronic diseases will remain and might even progress. Thus, fatigue levels comparable with those of the healthy workforce are not to be expected at follow-up. Nevertheless fatigue complaints continued to diminish in the second year for the experimental group, whereas they stabilized after
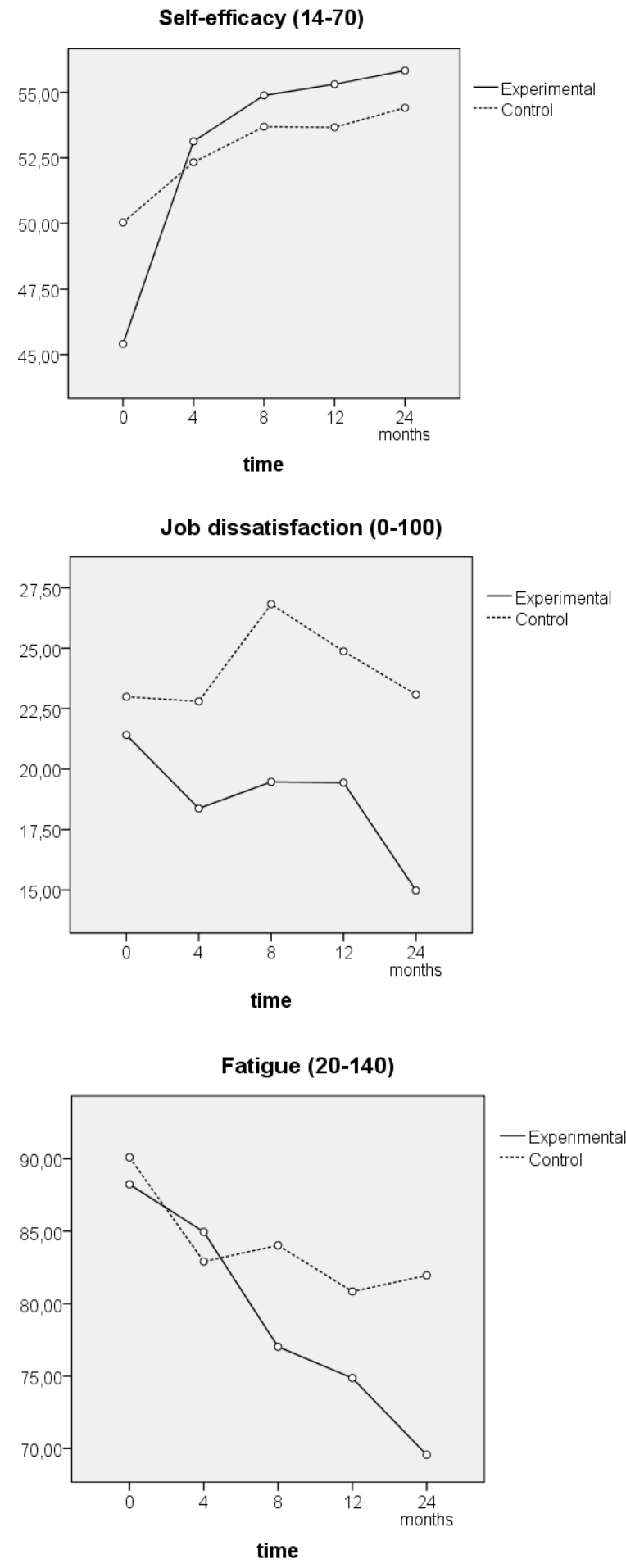

Figure 3. Effect of Intervention on self-efficacy, job dissatifaction, and fatique. Repeated measurement based on intention-to-treat analysis 
the first year for the control group. This indicates that the new attitudes and skills acquired in the intervention group probably need time to be fully realized and result in better and less fatiguing working conditions. We hypothesized that the intervention would increase self-efficacy leading to increased skills in communicating about the disease at work, better realization of work accommodations and thus a decrease in fatigue and job dissatisfaction. However, we did not find an increase in the number of work accommodations. In our process evaluation, we found that psychosocial factors may have a beneficial effect on their own, apart from their possible beneficial influence on the implementation of work accommodations. Job maintenance remained high in the whole group which resulted, as expected, in too low power to show any significant changes in spite of our long-term follow-up. Based on other work, we assume that less fatigue will lead to more job maintenance in the long run (24).

This RCT was not double blinded. The researcher knew to which group respondents were randomized. In addition, two of the researchers were developers of the intervention, which makes them more interested in a positive than negative outcome. As all outcome measures are self-report measures, we do not expect that this has caused bias. However, the most severe limitation of our study is that we could not blind participants to their control group status. Of the control group participants, $71 \%$ stated that they or others, (eg, the occupational physician, another medical professional, or the supervisor) undertook actions to solve work-related problems. The great majority of them stated that they did so because they were randomized to the control group. Many took steps comparable to the training program. Thus, participation in the trial probably functioned as an intervention in itself. This kind of contamination effect could have resulted in an underestimation of the impact of the intervention (37).

Women, higher-educated workers, and employees working in the service sector were over-represented in our sample. The small loss to follow-up might point to an over-representation of employees that are highly motivated to stay at work. These selection biases limit the external validity of our study. We do not know whether the effect of the intervention will be higher or lower in other study groups.

Several other studies assessed the effect of job maintenance programs with a randomized controlled design (38-41) or a non-randomized controlled design (42). Most did not find an effect on job maintenance but some found that the intervention decreased fatigue or increased self-efficacy in line with our findings. Purdon et al (41) studied the effect of a workplace intervention in a large group of 2845 employees on sick leave for 6-26 weeks. Job maintenance was not higher in the experimental group. One explanation for this negative finding was that the interventions offered were not always seen as fully meeting the clients' needs. The other explanation was that participants in the control group were very proactive on their own behalf. Two other studies did not find an effect on job maintenance either $(38,40)$. However, in one of these, de Buck et al (40) found a significant difference in fatigue between the experimental and control groups in favor of the experimental group. Rasgon et al (42) who studied dialysis patients, known for a low employment rate, found an effect on job maintenance for blue- but not white-collar workers. Allaire and colleagues (39) studied rheumatic diseases and found no difference after one year but a significant difference after two years. Self-efficacy in work accommodation request procedures was examined in two controlled studies, and an effect was found in one study but not the other $(43,44)$.

In future research, the problem that participants in the control group or their representatives aim at "substitution therapies" should be better addressed. One potential solution to this is a more solid embedding of this kind of research in occupational healthcare centers or outpatient clinics and the use of cluster randomization, which may prevent contamination effects (45). More cooperation with occupational healthcare centers or outpatient clinics could also help to incorporate groups that were under-represented in our project, such as men, less-educated individuals, or those working in transport or industry. Another solution to the problem of contamination resulting from the use of a non-blinded control group is to use a pre-study randomization design, in which participants are randomized before they are asked to consent and where only participants in the experimental group are asked to consent (46). Study designs without a control group, such as an interrupted time series or a pre-test/post-test design can be considered as well. In that case, more data on general changes in fatigue and job dissatisfaction would have to be gathered for this target group or for various groups of diseases with differing long-term prognoses. This kind of clinical data bases will teach us more about clinically relevant changes in outcome measures (47).

In conclusion, empowerment training increases selfefficacy in solving work- and disease-related problems and helps to reduce fatigue complaints, which in the long term could lead to more job maintenance. Better understanding of the ways to deal with the work-related problems of employees suffering from chronic diseases is needed to develop more efficient support for such individuals. 


\section{Acknowledgements}

The Dutch Ministry of Social Affairs and Employment and the Foundation Institute Gak (Stichting Instituut Gak) financially supported the development and realization of the intervention as well as the study. The occupational health service provider ArboUnie supported the development and realization of the intervention.

Trial registration: ISRCTN77240155. The authors declare that they have no competing interests. Two of the authors have entered into consultation with an organization that may organize the training program.

\section{References}

1. Lerner DJ, Amick BC, III, Malspeis S, Rogers WH. A national survey of health-related work limitations among employed persons in the United States. Disabil Rehabil. 2000; 22:22532. doi:10.1080/096382800296791.

2. Detaille SI, Haafkens JA, Van Dijk FJH. What employees with rheumatoid arthritis, diabetes mellitus and hearing loss need to cope at work. Scand J Work Environ Health. 2003;29:134-42.

3. Nilsson I, Fitinghoff H, Lilja M. Continuing to work after the onset of rheumatoid arthritis. Work. 2007;28:335-42.

4. Banks P, Lawrence M. The Disability Discrimination Act, a necessary, but not sufficient safeguard for people with progressive conditions in the workplace? The experiences of younger people with Parkinson's disease. Disabil Rehabil. 2006;28:13-24. doi:10.1080/09638280500165120.

5. Mancuso CA, Rincon M, Sayles W, Paget SA. Longitudinal study of negative workplace events among employed rheumatoid arthritis patients and healthy controls. Arthritis Rheum. 2005;53:958-64. doi:10.1002/art.21594.

6. Lacaille D, White MA, Backman CL, Gignac MA. Problems faced at work due to inflammatory arthritis: new insights gained from understanding patients' perspective. Arthritis Rheum. 2007;57:1269-79. doi:10.1002/art.23002.

7. Gustafsson M, Ekholm J, Ohman A. From shame to respect: musculoskeletal pain patients' experience of a rehabilitation programme, a qualitative study. J Rehabil Med. 2004;36:97103. doi:10.1080/16501970310018314.

8. Swain MG. Fatigue in chronic disease. Clin Sci. 2000;99(1):18. doi:10.1042/CS19990372.

9. Donders NC, Roskes K, van der Gulden JW. Fatigue, emotional exhaustion and perceived health complaints associated with work-related characteristics in employees with and without chronic diseases. Int Arch Occup Environ Health. 2007;80:577-87. doi:10.1007/s00420-006-0168-6.

10. Franssen PM, Bultmann U, Kant I, van Amelsvoort LG. The association between chronic diseases and fatigue in the working population. J Psychosom Res. 2003;54:339-44. doi:10.1016/S0022-3999(02)00395-1.
11. Allaire S, Wolfe F, Niu J, Lavalley MP. Contemporary prevalence and incidence of work disability associated with rheumatoid arthritis in the US. Arthritis Rheum. 2008; 59:47480. doi:10.1002/art.23538.

12. Verstappen SM, Boonen A, Bijlsma JW, Buskens E, Verkleij $\mathrm{H}$, Schenk Y et al. Working status among Dutch patients with rheumatoid arthritis: work disability and working conditions. Rheumatology. 2005;44:202-6. doi:10.1093/rheumatology/ keh400. doi:10.1093/rheumatology/keh400.

13. Feagan BG, Bala M, Yan S, Olson A, Hanauer S. Unemployment and disability in patients with moderately to severely active Crohn's disease. J Clin Gastroenterol. 2005; 39:390-5. doi:10.1097/01.mcg.0000159220.70290.41.

14. Longobardi T, Jacobs P, Bernstein CN. Work losses related to inflammatory bowel disease in the United States: results from the National Health Interview Survey. Am J Gastroenterol. 2003;98:1064-72.

15. Longobardi T, Jacobs P, Wu L, Bernstein CN. Work losses related to inflammatory bowel disease in Canada: results from a National Population Health Survey. Am J Gastroenterol. 2003;98:844-49. doi:10.1111/j.1572-0241.2003.07378.x.

16. de Boer AG, Taskila T, Ojajarvi A, van Dijk FJ, Verbeek JH. Cancer survivors and unemployment: a meta-analysis and meta-regression. JAMA. 2009;301:753-62. doi:10.1001/ jama.2009.187.

17. Kremer AM, Pal TM, van Keimpema AR. Employment and disability for work in patients with COPD: a cross-sectional study among Dutch patients. Int Arch Occup Environ Health. 2006;80:78-86. doi:10.1007/s00420-006-0101-z.

18. Kutner N, Bowles T, Zhang R, Huang Y, Pastan S. Dialysis facility characteristics and variation in employment rates: a national study. Clin J Am Soc Nephrol. 2008;3:111-116. doi:10.2215/CJN.02990707.

19. Martikainen KK, Luukkaala TH, Marttila RJ. Parkinson's disease and working capacity. Mov Disord. 2006; 21:2187-91. doi:10.1002/mds.21171.

20. Pompeii LA, Moon SD, McCrory DC. Measures of physical and cognitive function and work status among individuals with multiple sclerosis: a review of the literature. J Occup Rehabil. 2005;15:69-8. doi:10.1007/s10926-005-0875-y.

21. ACOEM Committee. Preventing needless work disability by helping people stay employed. J Occup Environ Med. 2006;48:972-87. doi:10.1097/01. jom.0000235915.61746.0d.

22. Lerner D, Allaire SH, Reisine ST. Work disability resulting from chronic health conditions. J Occup Environ Med. 2005;47:253-64. doi:10.1097/01.jom.0000150206.04540.e7. doi:10.1097/01.jom.0000150206.04540.e7.

23. Varekamp I, Verbeek JH, van Dijk FJ. How can we help employees with chronic diseases to stay at work? A review of interventions aimed at job retention and based on an empowerment perspective. Int Arch Occup Environ Health. 2006;80:87-97. doi:10.1007/s00420-006-0112-9.

24. van Amelsvoort LG, Kant IJ, Beurskens AJ, Schroer CA, Swaen GM. Fatigue as a predictor of work disability. Occup 
Environ Med. 2002;59:712-3. doi:10.1136/oem.59.10.712.

25. Hoogendoorn WE, Bongers PM, de Vet HC, Ariens GA, van MW, Bouter LM. High physical work load and low job satisfaction increase the risk of sickness absence due to low back pain: results of a prospective cohort study. Occup Environ Med. 2002;59:323-8. doi:10.1136/oem.59.5.323.

26. Feste C, Anderson RM. Empowerment: from philosophy to practice. Patient Educ Couns. 1995;26:139-44. doi:10.1016/0738-3991(95)00730-N.

27. Bandura A. Self-efficacy: toward a unifying theory of behavioral change. Psychol Rev. 1977;84:191-215. doi:10.1037/0033-295X.84.2.191.

28. Varekamp I, de Vries G, Heutink A, van Dijk FJ. Empowering employees with chronic diseases; development of an intervention aimed at job retention and design of a randomized controlled trial. BMC Health Serv Res. 2008;8:224. doi:10.1186/1472-6963-8-224.

29. Beurskens AJ, Bultmann U, Kant I, Vercoulen JH, Bleijenberg G, Swaen GM. Fatigue among working people: validity of a questionnaire measure. Occup Environ Med. 2000; 57:353-7. doi:10.1136/oem.57.5.353

30. Stulemeijer M, de Jong LW, Fiselier TJ, Hoogveld SW, Bleijenberg G. Cognitive behaviour therapy for adolescents with chronic fatigue syndrome: randomized controlled trial. BMJ. 2005;330:14. doi:10.1136/bmj.38301.587106.63.

31. Bandura A. Guide for constructing self-efficacy scales. In Self-Efficacy Beliefs of Adolescents. [Cited 4 February 2010, available from http://www.des.emory.edu/mfp/014BanduraGuide2006.pdf]. Charlotte (NC, USA):Information Age Publishing. 2006. p307-337.

32. Bultmann U, de VM, Beurskens AJ, Bleijenberg G, Vercoulen $\mathrm{JH}$, Kant I. Measurement of prolonged fatigue in the working population: determination of a cutoff point for the checklist individual strength. J Occup Health Psychol. 2000;5:411-416. doi:10.1037/1076-8998.5.4.411.

33. Van Veldhoven MMT. Het meten van psychosociale arbeidsbelasting met een vragenlijst: De Vragenlijst Beleving en Beoordeling van de Arbeid [Measuring psychosocial burden of work with a questionnaire: Questionnaire on Perception and Judgment of Work]. Amsterdam: Nederlands Instituut voor Arbeidsvraagstukken [Netherlands Institute for Labour Issues]. 1994.

34. Maurischat C, Ehlebracht-Konig I, Kuhn A, Bullinger M. Factorial validity and norm data comparison of the Short Form 12 in patients with inflammatory-rheumatic disease. Rheumatol Int. 2006;26:614-21. doi:10.1007/s00296-0050046-7.

35. Schaufeli WB, van Dierendonck D. Utrecht Burnout Scale: Manual (UBOS 2000). Lisse: Swets Test Publishers; 2000.
36. Varekamp I, Krol B, van Dijk F. Empowering employees with chronic diseases: Process evaluation of an intervention aimed at job retention. Int Arch Occup Environ Health. 2011; 84:35-43. doi:10.1007/s00420-010-0577-4.

37. Victora CG, Habicht JP, Bryce J. Evidence-based public health: moving beyond randomized trials. Am J Public Health. 2004;94:400-5. doi:10.2105/AJPH.94.3.400.

38. LaRocca NG, Kalb RC, Gregg K. A program to facilitate retention of employment among persons with multiple sclerosis. Work. 1996;7:37-46. doi:10.1016/1051-9815(96)00186-6.

39. Allaire SH, Li W, LaValley MP. Reduction of job loss in persons with rheumatic diseases receiving vocational rehabilitation. Arthritis Rheum. 2003;48:3212-8. doi:10.1002/ art.11256.

40. de Buck PD, le Cessie S, van den Hout WB, Peeters AJ, Ronday HK, Westedt ML et al. Randomized comparison of a multidisciplinary job-retention vocational rehabilitation program with usual outpatient care in patients with chronic arthritis at risk for job loss. Arthritis Rheum. 2005;53:682-90. doi:10.1002/art.21452.

41. Purdon S, Stratford N, Taylor R, Natarajan L, Bell S, Wiitenburg D. Impacts of the Job Retention and Rehabilitation Pilot. Research Report No 342. Leeds: Department for Work and Pensions. 2006.

42. Rasgon S, Schwankovsky L, James-Rogers A, Widrow L, Glick J, Butts E. An intervention for employment maintenance among blue-collar workers with end-stage renal disease. American Journal of Kidney Diseases. 1993;22:403-12.

43. Rumrill PD, Garnette M. Career adjustment via reasonable accommodations: the effects of an employee-empowerment intervention for people with disabilities. Work. 1997; 9:57-64. doi:10.1016/S1051-9815(97)00023-5.

44. Rumrill PD. Effects of a social competence training program on accommodation request activity, situational self-efficacy, and Americans with disabilities act knowledge among employed people with visual impairments and blindness. Journal of Vocational Rehabilitation. 1999;12:25-31.

45. Ukoumunne OC, Gulliford MC, Chinn S, Sterne JA, Burney PG. Methods for evaluating area-wide and organization-based interventions in health and health care: a systematic review. Health Technol Assess. 1999;3:iii-92.

46. Schellings R, Kessels AG, ter RG, Sturmans F, Widdershoven GA, Knottnerus JA. Indications and requirements for the use of prerandomization. J Clin Epidemiol. 2009; 62:393-9. doi:10.1016/j.jclinepi.2008.07.010.

47. Black N. High-quality clinical databases: breaking down barriers. Lancet. 1999; 353:1205-6. doi:10.1016/S01406736(99)00108-7

Received for publication: 8 September 2010 